\title{
A REPRESENTAÇÃO SOCIAL DAS ADOLESCENTES SOBRE A GRAVIDEZ NESTA ETAPA DE VIDA
}

\author{
The social representation of the adolescents on the \\ pregnancy in this lives stage
}

\author{
A representación social de los adolescentes en el embarazo \\ en esta etapa de vida
}

Débora Luiza de Oliveira Rangel ${ }^{1}$

Ana Beatriz Azevedo Queiroz ${ }^{2}$

\section{RESUMO}

Trata-se de apreender as representações sociais das adolescentes acerca da gravidez nesta etapa de vida. Abordagem qualitativa na perspectiva da Teoria das Representações Sociais de Moscovici, com adolescentes não grávidas e com atividade sexual. Os cenários foram escolas privadas e públicas do Rio de Janeiro. Para a coleta de dados, utilizaram-se técnica expressiva e entrevista semi-estruturada. As informações foram tratadas segundo a análise de conteúdo. As adolescentes representam a gravidez como mudança geradora de responsabilidades e não ser esta a idade ideal para vivenciar esse momento. A representação teve uma ligação com o nível sócio-econômico-demográfico: as mais favorecidas acreditam que a gravidez nessa fase seria um destruidor de planos futuros. 0 segmento oposto representou a gestação como identidade "natural do feminino". Tais evidências denotam a necessidade de os profissionais de saúde atentarem para a diversidade de pertenças sociais-culturais-econômicas, visando proporcionar autonomia na escolha do momento da gravidez e garantir os direitos sexuais e reprodutivos.

Palavras-chave: Gravidez. Adolescente. Enfermagem

\begin{abstract}
This work deals with the representations of the female adolescents concerning the pregnancy in this stage of life and intends to apprehend the content/structure of the social representations concerning the pregnancy in the adolescence. The theoretical framework for social representation used was the Moscovici's, approach was qualitative, having as subjects forty sexually active non pregnant adolescents and, as scene, Rio de Janeiro's schools. From the social-economic-demographic profile of the adolescents an expressive technique and a half-structuralized interview were performed. The data according to Bardin's content analysis point to favorable and unfavorable extremities of the representation of the object. It emerged as something inadequate, generator of responsibilities and moral judgment. It is noticeable the link between such representations and the social-economic level: the most privileged ones evidenced that it can jeopardize future plans, however, the other segment emphasizes the crowning of the natural identity of the feminine. At last it is necessary to attempt to the diversity in the groups in order to propitiate greater autonomy to choose the moment of the pregnancy.
\end{abstract}

\section{Resumen}

Este trabajo se ocupa de las representaciones de las adolescentes referentes al embarazo en esta etapa de la vida y objetiva aprehender el contenido/la estructura de las representaciones sociales referentes al embarazo en la adolescencia. La abordaje teórica fue cualitativa, teniendo como sujetos cuarenta adolescentes no embarazadas sexualmente activas y, como escenario, escuelas de Río de Janeiro. Del perfil socio-económico-demográfico de las adolescentes he realizado la técnica expresiva y entrevista semi-estructurada. Los datos tratados conforme el análisis del contenido de Bardim, apuntan polos favorables y desfavorables de la representación del objeto. Esto emergió como algo inadecuado, generador de responsabilidades y juicio moral. Es observada vinculación directa entre tales representaciones y el nivel socio-económico: las mas favorecidas evidencian su carácter comprometedor de los planes futuros, ya el seguimiento opuesto resalta la coronación de la identidad natural del femenino. Se concluye, destacando la necesidad de atentarnos acerca de la diversidad de los grupos, para propiciar mayor autonomía en la opción del momento del embarazo. 


\section{INTRODUCÃO}

Este trabalho tem como objeto de estudo as representações sociais das adolescentes sobre a gravidez nesta etapa de vida.

Diante da convivência profissional de grupos educativos com os adolescentes, pudemos perceber que era comum emergirem questionamentos advindos das experiências particulares, e a temática sexualidade estava presente em nossas discussões. A existência de muitas dúvidas, medos, tabus e preconceitos era uma constante que rodeava esta temática, fato que pode ser explicado pelo nosso contexto sócio-históricocultural, em que as questões que perpassam pelo campo da sexualidade são envoltas em uma rede de convenções, regras e juízos.

A sociedade desempenha importante papel no estabelecimento e manutenção de tabus, preconceitos, crenças e sentimentos das pessoas a respeito da sexualidade ${ }^{1}$, o que resulta na dificuldade que os indivíduos têm em lidar com questões referentes à sexualidade.

Tendo em vista o adolescer como processo de construção da identidade do adolescente, e a imensidão de transformações decorrentes desse processo, destacamos que as manifestações da sexualidade assumem significações particulares. A sexualidade vivida pelo adolescente ganha afeição do contexto cultural em que se insere, ou seja, a sexualidade é permeada pelos valores vigentes nessa época².

No momento atual, início do século XXI, o mundo vivencia uma época de constante revolução sexual, presencia-se o sexo na mídia, nudez e pornografia. Mas apesar desta crescente veiculação, ainda predomina, em nossa sociedade, o ideário de sexualidade enquanto objeto de tabu. A qualidade da informação não acompanha a qualidade da comunicação e, conseqüentemente, compromete a formação do adolescente no que tange ao exercício pleno de sua sexualidade.

Desta forma, o adolescente contemporâneo vive em meio a referências ambíguas que invadem seu imaginário. De um lado, a liberdade característica do contexto pós-moderno da vivência do sexo, e, de outro, os arquétipos moralistas de nossa cultura arraigada nos princípios judáico-cristãos.

Neste contexto, estabelecem-se obstáculos já que a temática cristaliza-se em si mesma enquanto conteúdo interdito, velado e ilícito, acarretando certa negligência com relação à educação sexual de crianças e adolescentes.

De modo global, isso é refletido nas escolas, nas unidades de saúde ou em casa, constatando-se a incipiência das abordagens do tema sexualidade entre a população adolescente. Ocorre uma ineficácia em relação à formação da aliança comunicativa na qual a adolescente encontre espaço e apoio para expressar-se enquanto sujeito de seu contexto histórico, social, econômico, político e cultural.

No entanto, a experiência de trabalhar com adolescentes nos levou a observar que a maior interpelação em torno da sexualidade gravita em torno da temática gravidez, principalmente entre as meninas, trazendo uma diversidade de ações e reações diante da possibilidade de uma gravidez nesta fase de vida.

Esta predominância do interesse das adolescentes no que abrange os aspectos que circundam a gravidez pode estar associada ao imaginário social que consagra a mulher como a responsável principal pela geração de filhos. Isso porque ainda predominam, nos dias atuais, os pressupostos ideológicos e culturais da procriação enquanto "natureza da mulher", em conseqüência direta de sua fisiologia reprodutiva; ou seja, sendo a mulher que engravida, cabe a ela se preocupar com tal questão ${ }^{3}$.

Tal realidade também é relacionada com as desigualdades de gênero presentes em nossa sociedade, uma vez que esta classifica direitos e deveres de homens e mulheres de modo hierarquizado no âmbito da sexualidade, atribuindo à mulher a responsabilidade quanto às práticas de concepção e contracepção e exigindo do homem freqüente demonstração de virilidade ${ }^{4}$.

Assim, diante da freqüência da problemática ora descrita, delimitamos a seguinte questão do estudo: como as adolescentes que não estão grávidas, mas vivenciam a possibilidade de uma gestação, representam a gravidez na adolescência?

0 objetivo a ser contemplado durante o desenvolvimento deste trabalho é: apreender o conteúdo das representações sociais (RS) acerca da gravidez na adolescência, sob a ótica das próprias adolescentes.

\section{METODOLOGIA}

A Teoria das Representações Sociais de Serge Moscovici ${ }^{5 ;}$ ${ }^{124}$ foi utilizada na fundamentação da abordagem qualitativa, a qual, segundo Polit e Hungler "baseia-se na premissa de que os conhecimentos sobre os indivíduos só são possíveis com a descrição da experiência humana, tal como ela é vivida e tal como ela é definida por seus próprios atores".

0 conceito de representações sociais enfatiza que 0 indivíduo é produto da sociedade, que é dinâmica e fluida ${ }^{5}$. Então, o indivíduo, ao mesmo tempo em que é sujeito na construção das representações sociais, tem estas como elemento orientador de seus comportamentos. Ou seja, a representação social se propõe a dar conta de como o social transforma um conhecimento em representação, e como essa, por sua vez, transforma o social ${ }^{7}$

Como cenário de estudo foram adotadas unidades escolares do município do Rio de Janeiro, entre publicas e privadas. Partiuse do pressuposto da necessidade de uma prévia distinção com relação ao nível sócio-econômico-demográfico (NSED) das adolescentes, já que essa diferenciação acarretou heterogeneidade do objeto de representação. Para Wagner ${ }^{8}$,é evidente que as diversas condições sociais existentes nos grupos e sociedade são responsáveis por acarretar representações sociais distintas, evidenciando a forma com que cada grupo de pertença lida com determinados fenômenos. 
0 próprio desenrolar da pesquisa atribuiu certa peculiaridade a este agrupamento por NSED: todos os alunos vinculados à rede pública de ensino foram classificados como pertencentes ao NSED baixo, e, em contrapartida, todos os alunos ligados à esfera privada da educação, como grupo de NSED alto. A distinção de NSED alto e baixo caracteriza-se em um conceito próprio do estudo; para tanto, foram consideradas variáveis indicativas como: renda familiar, bairro, condições de moradia, fontes de lazer, dentre outras.

A seleção das participantes obedeceu a alguns critérios de inclusão, como serem as entrevistadas adolescentes do sexo feminino, pois a gravidez se objetiva no corpo da mulher. Tal realidade atribui a esta adolescente maior aproximação e identificação no que se relaciona com a vivência, propriamente dita, da gravidez.

0 segundo foi selecionar adolescentes que não tivessem vivenciado uma gestação a termo, não tivessem filhos, não estivessem grávidas ou tentando engravidar, uma vez que tal situação denotaria a "opção/aceitação" da vivência da maternidade, o que influenciaria nas representações sociais sobre o fenômeno estudado.

0 último critério diz respeito à vivência pela adolescente da possibilidade da gravidez. Para tanto, apoiamo-nos nos saberes compartilhados pelas próprias adolescentes ao inferirem que a possibilidade da gravidez relaciona-se com a iniciação sexual, independentemente do caráter esporádico ou não vigente na sua vida sexual.

Assim, totalizaram-se 40 sujeitos que originaram quatro subgrupos de pertença: 10 adolescentes de NSED baixo e faixa etária de 10 a 15 anos completos; 10 de NSED baixo e faixa etária de 16 a 19 anos completos; 10 de NSED alto e faixa etária de 10 a 15 anos completos; e 10 de NSED alto e faixa etária de 16 a 19 anos completos. A classificação da faixa etária se deu no decorrer do estudo, no qual se percebeu a diversidade de representações com relação a esses dois grupos de pertença: as adolescentes no início dessa fase e as adolescentes mais no final dessa etapa.

Com base nas características do objeto desta investigação e na perspectiva da Teoria das Representações Sociais pertinente, adotaram-se duas técnicas de coletas de informações individuais - técnica projetiva de corte e colagem e entrevista semi-estruturada. A técnica projetiva tinha a seguinte questão norteadora: o que seria para vocêficar grávida neste momento de sua vida, ou seja, em sua adolescência?

Após a realização da técnica expressiva, as adolescentes explanavam sobre suas produções artística. Após essa primeira etapa, era aplicada a técnica da entrevista semi-estruturada,

\section{RESULTADOS E DISCUSSÃO}

Com base no processo dinâmico envolto na elaboração pelas adolescentes das representações sociais acerca da gravidez neste período, buscou-se delinear o referencial explicativo presente em tais elaborações. Das representações das adolescentes sobre a gravidez neste período de suas vidas, foi possível evidenciar diferentes representações deste mesmo objeto, que emergiram a partir dos distintos contextos vivenciais das entrevistadas.

Destaca-se que o engravidar na adolescência depreende duas conotações com polaridades inversas - condicionantes negativos e positivos - capazes de compreender toda a gama de representações que traduzem os modos de reconstrução das noções circulantes acerca do fenômeno estudado pelas adolescentes entrevistadas.

Deste modo, edifica-se sobre o pilar de aspecto desfavorável todo o leque de eventos tidos como onerosos para o ser adolescente do sexo feminino. Nesta perspectiva, o engravidar na adolescência constitui-se em núcleo de representação de caráter negativo, que, por conseguinte, acaba figurando enquanto componente orientador das interpretações das adolescentes sobre o mundo e sobre si mesmas no que tange à questão da gravidez, repercutindo, inclusive, nas práticas cotidianas destas adolescentes.

\section{CATEGORIA I: Gravidez na Adolescência: Não é Hora!}

Para as adolescentes deste estudo, na totalidade 40 depoentes, a gravidez neste período foi representada como uma antecipação, algo inadequado, precipitado e fora do momento oportuno. 0 ideário de ausência de prontidão da adolescente com relação à gravidez se fez marcante, e a representação da gravidez na adolescência surge como algo "fora de hora".

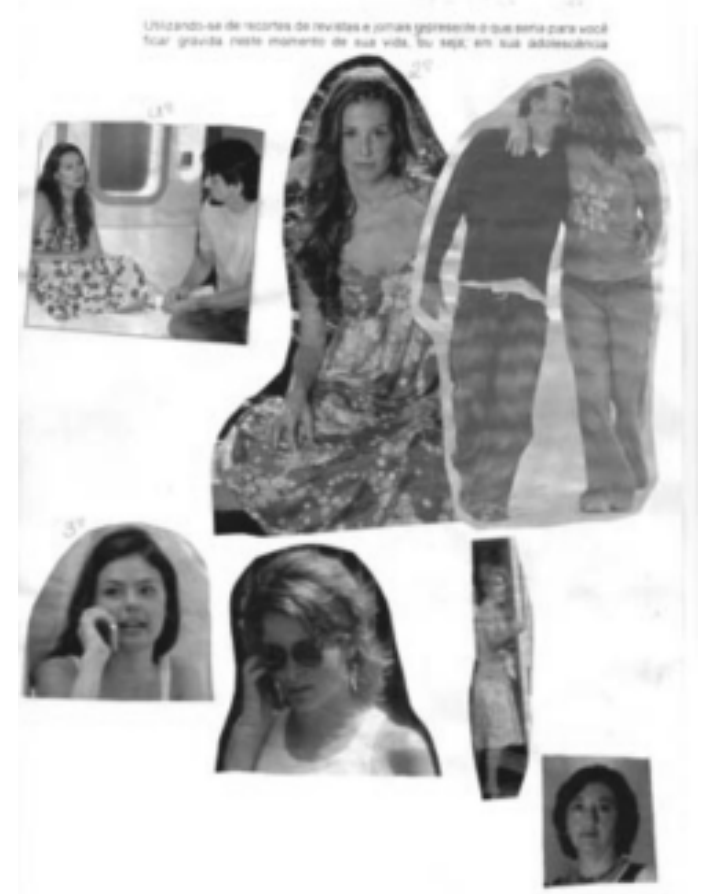


Seria algo fora do tempo. Acredito que tudo na vida tem um tempo e se eu ficasse grávida agora ia ser algo num tempo errado (...) errado porque eu estaria modificando drasticamente a minha vida, eu tenho 15 anos ainda. -( E21 - 15 anos/NSED baixo)

Agora a gravidez seria uma bomba na minha mão, porque eu não estou preparada para ser mãe, mentalmente, fisicamente em nada... Agora seria uma bomba para mim. (E34 - 19 anos/NSED alto

Tal conteúdo de precipitação permeou o universo corrente do discurso das depoentes, independentemente do NSED ou do fator idade, e consolidou-se, neste estudo, como uma representação hegemônica, transpondo horizontalmente as falas e denotando certa homogeneidade no que tange a esta faceta da representação social da gravidez.

Em nossa sociedade, vigora, enquanto componente central das representações sobre gravidez na adolescência, um conjunto de concepç̃̃es que atrelam e significam a adolescência como etapa de transição, caracterizada por uma progressiva emancipação, capaz de culminar na aquisição de autonomia material e na constituição de uma unidade conjugal e/ou familiar própria.

Pode-se ainda perceber o processo de objetivação das representações sociais, quando a E34 se refere à gravidez nesse período como uma bomba, pois este é o processo pelo qual se estabelece o concreto naquilo que é abstrato, ou seja, desconhecidas noções, idéias e imagens são transformadas em forças concretas que constituem a realidade ${ }^{10}$.

Assim, as adolescentes, ao representarem a gravidez na adolescência, integram cognitivamente o caráter inopor tuno da mesma a um sistema de pensamento social preexistente. Esse processo é conhecido como ancoragem e é responsável pelo enraizamento das idéias. Para isso, as adolescentes lançaram mão de suas redes de significações prévias e teceram certa forma de conhecimento prático que culminou na incorporação da representação que refuta a adolescência enquanto momento ótimo para se engravidar. É através deste processo de ancoragem que o objeto gravidez na adolescência e sua representação enquanto algo fora de hora foram situados em relação aos valores sociais, e se investiram de coerência.

\section{CATEGORIA II: Julgamento Moral da Adolescente que Engravida}

Ainda sobre a "matriz" cognitiva do objeto gravidez na adolescência e seu conjunto de impressões, afetos, cognições e imagens capazes de possibilitar que as adolescentes compreendam o engravidar na adolescência e adotem condutas e posturas diante desta questão, é impor tante mencionar o destaque atribuído pelas adolescentes ao julgamento moral que repercute sobre a adolescente que engravida.
Esta representação de julgamento moral sobre a adolescente que engravida evidenciou-se, também, como determinante negativo da gravidez na adolescência e como hegemônica para o grupo estudado, pois permeou 39 dos discursos, independentemente dos subgrupos de pertença.

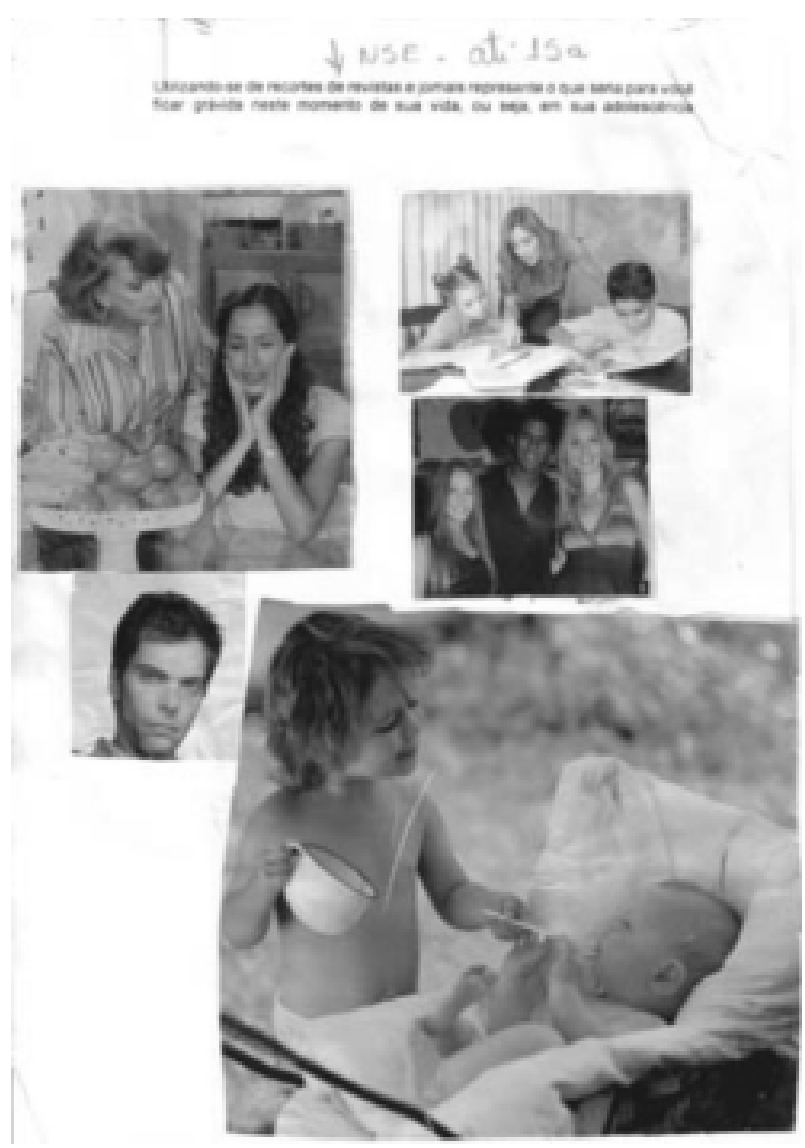

Eu acho que seria uma tristeza para mim... Eu ia perder tudo. Eu ia perder principalmente o amor dos meus pais, [...] eles iam ficar decepcionados comigo. Eles esperam que eu não seja como estas meninas que só querem namorar e ir para o baile. Se eu tivesse um filho adolescente eu ia estar indo pelo caminho delas, estaria me igualando. - (E913 anos/NSED baixo)

A maioria das pessoas julgava ela... Julgavam dizendo assim: que ela era oferecida, que mal conhecia o cara e já foi tendo relação com ele.... Já que você foi oferecida, você vai ter esse bebê agora para aprender como é a vida - (E02- 15 anos/ NSED baixo)

Neste caso, o acontecimento de uma gravidez na adolescência é associado a um julgamento preestabelecido, no qual a mulher que engravida fora do casamento, é, moralmente, mal vista. Isto acontece, pois o casamento, ainda hoje, permanece como uma elaboração social que simboliza a mulher respeitável. As mulheres que fogem a este modelo rompem com a equação esposa-mãe e expõe-se a serem rotuladas com adjuntos adnominais semanticamente carregados de 
preconceitos: "mulher à-toa, de má nota, errada, perdida, vadia"11.

Assim, o espaço do casamento permanece soberano em seu papel fundador das representações da gravidez. Nem mesmo as transformações que vêem marcando a vida das mulheres nas últimas décadas foi suficiente para desfigurarem a crença de que a atividade sexual feminina é algo profano, com exceção de quando esta se destina a cumprir as funções sociais do casamento e maternidade.

A forte aderência destas crenças no universo da subjetividade feminina das adolescentes nos remete às formulações de $\mathrm{Abric}^{12}$ ao explicar a lentidão do processo de mudança das representações sociais. Neste caso, são exatamente os componentes centrais (modelo esposa-mãe) os responsáveis pela dinâmica interna de ressignificação/manutenção que acompanha o processo de reorganização dos componentes representacionais diante das novas informações provenientes da realidade.

Estas adolescentes vivenciam a ambigüidade na construção de sua identidade e subjetividade feminina, pois, apesar do sexualismo difuso na sociedade que lhes apresenta certa legitimidade perante o exercício da atividade sexual, devem pautar suas atividades sexuais pré-conjugais em um círculo de sigilo, atentando para o caráter violável do advento gravidez.

\section{CATEGORIA III: Sobrecarga Financeira}

Neste estudo, outro condicionante negativo da representação social da gravidez na adolescência foi a sobrecarga financeira. Esta emergiu como a terceira categoria com maior quantitativo, totalizando 17 adolescentes.

Porque não adianta a gente ter um filho e não ter condição de criar. [...] para não precisar pedir nada para os outros, assim: Ah! Me dá... Eu não tenho leite, vou pedir na porta de alguém. Não ter uma fralda e pedir. No meu entendimento, é assim. A gente tem que ter um filho sabendo que a gente tem condição de criar. -( E10 - 15 anos/NSED baixo)

Esta perspectiva deixa-nos perceber que vigora, no dia-adia das adolescentes, um conjunto de conceitos, afirmações, explicações que teorizam o senso comum de que a adolescente não vivencia a estabilidade financeira para o sustento de uma criança. Mais que uma nova fonte de gastos, a gravidez é tida como despesa de administração inviável e incompatível com a realidade financeira da adolescente.

Foi possível destacar que a variável NSED se fez fortemente presente enquanto componente aglutinador dos subgrupos de pertença. A representação de sobrecarga financeira para a gravidez na adolescência foi expressa somente pelas adolescentes de NSED baixo quando buscavam explicar o objeto em estudo. Isto porque o cotidiano de privação econômica das adolescentes provenientes das camadas de baixa renda acaba por se caracterizar em elemento capaz de dar sentido às ações destas adolescentes.

Estamos diante de uma perspectiva de percepção de mundo que influencia, inclusive, o modo com que estas adolescentes percebem e pensam a gravidez. É todo um saber prático que orienta o movimento cognitivo das adolescentes na classificação e valoração da gravidez na adolescência como um aspecto negativo devido à situação financeira onerosa incompatível com a renda familiar.

\section{CATEGORIA IV: Comprometimento de Planos Futuros}

Ainda, tendo como base as elaborações das entrevistadas em torno da temática gravidez na adolescência, salientamos a representação da gravidez na adolescência estruturada a partir do comprometimento de planos futuros, sejam eles de âmbito profissional ou não. Vejamos a colagem a seguir com sua descrição:

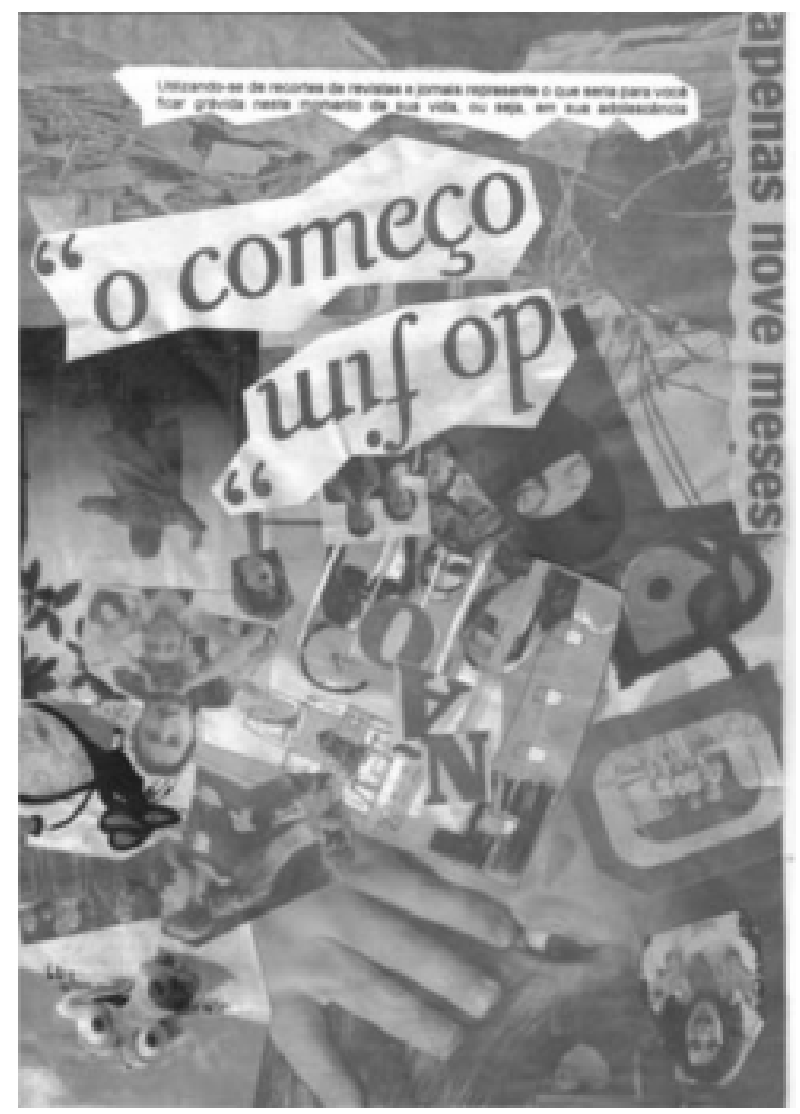

O caos que ficaria na minha vida[...] As figuras de cabeça pra baixo, assim como iria colocar minha vida de ponta-cabeça... Mudar minha rotina, meu modo de pensar e agir. E a palavra "FIM" bem grande, claro, porque seria o fim da minha adolescência, eu ia ter que virar adulta de uma vez por ter que trabalhar. la abrir mão dos meus planos, meus estudos, terminar minha faculdade $e$ conseguir um bom emprego na aviação. (E 33 17 anos/NSED alto) 
Essa representação foi expressa primordialmente pelas adolescentes de NSED alto (de 20 adolescentes desse segmento, 13 tiveram essa representação), uma vez que traduziu proximidade na relação deste grupo com o objeto socialmente valorizado: a gravidez na adolescência. É pertinente ressaltar que a variável NSED se caracterizou enquanto crivo de identificação entre os grupos de pertença.

A explicação para esta diferença de representação provavelmente se relaciona à heterogeneidade das trajetórias juvenis existentes no Brasil, particularmente quanto ao processo de escolarização e à inserção no mercado de trabalho.

Entre os grupos sociais mais favorecidos, observa-se um aumento do tempo de estudo, a manutenção do tempo de coabitação com os pais e a aquisição tardia da autonomia material ${ }^{13}$.

A condição de pobreza e a necessidade de busca constante por recursos para a sobrevivência acabam por restringir as perspectivas de oportunidades futuras (estudo, emprego, entretenimento, etc) das adolescentes do NSED baixo. Observase um caráter mais imediatista nas perspectivas de trabalho ou formação profissional, respaldada pela precariedade das condições de vida das adolescentes ${ }^{14}$. Uma constatação oposta se evidencia no grupo de NSED alto, para o qual a adolescência é um momento gerador e propiciador de oportunidades capazes de enriquecer a bagagem individual, potencializando e viabilizando novos planos (pessoais ou profissionais) a curto ou longo prazo.

Essas adolescentes de NSED alto, ao representarem a gravidez como algo capaz de comprometer planos futuros, incluindo 0 âmbito público neste ideário, demonstram que a vida feminina pode ter dimensões ampliadas no mundo contemporâneo, fora dos estritos limites impostos pela cultura/ sociedade tradicional. Atualmente, mesmo a maternidade se mantendo no plano da "ordem da lel" (cultural) para o ser mulher, ela já não se apresenta como única e exclusivamente uma "ordem natural" 15.

\section{CATEGORIA V: A Difícil Transição: de Cuidada para Cuidadora}

Esta categoria emergiu num total de nove aparições e reflete o caráter pesaroso atribuído à gravidez na adolescência enquanto elemento propulsor da ruptura com o papel social de cuidada e incorporação das atribuiç̃̃es de cuidadora. Esta categoria emerge enquanto representação capaz de identificar, descrever e articular os sistemas de valores, idéias e práticas que acabam por permitir as adolescentes "orientarem-se em seu mundo material e social, controlando-o, a partir de elementos de sua história individual e grupa ${ }^{16}$. A figura abaixo e sua descrição elucidam essa categoria:
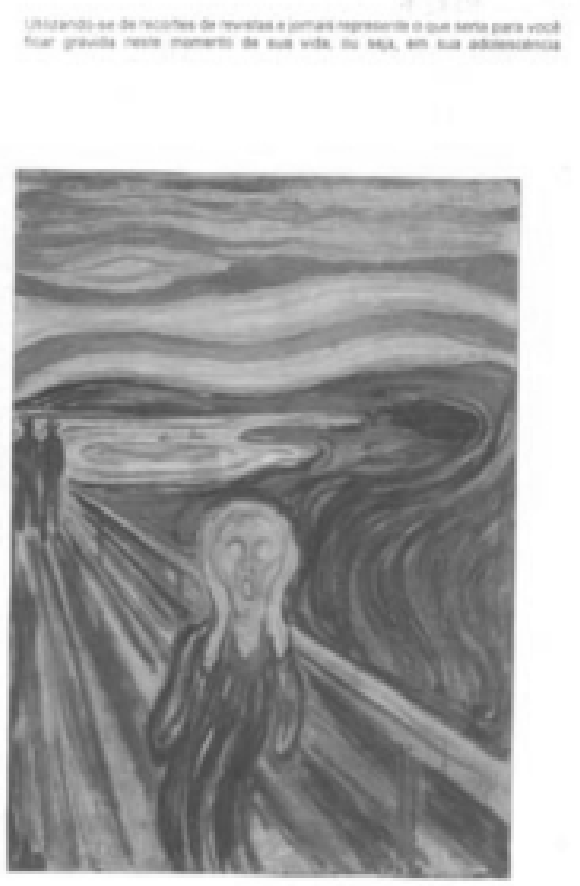

Eu estou nova... não tenho condições de me cuidar, imagina, de uma criança, pois não sei cozinhar, arrumar a casa. Quando estou doente se não é a minha mãe para cuidar de mim, continuo doente. Não tenho responsabilidade suficiente para cuidar de duas pessoas: eu e o meu filho. [...] Eu prefiro continuar assim, não ter responsabilidade, não ter que cuidar de ninguém, só viver e saber que tem alquém que se preocupa por você e com você. No caso a minha mãe[...] - (E22 - 15 anos/NSED alto)

A gravidez na adolescência é representada pelas adolescentes do estudo como ascensão a um novo lócus social, já que sua identidade social deixa de ser a de filha e passa a ser definida como mãe. Esta troca de papéis no seio da estrutura familiar, tradicional nicho de reconhecimento social da mulher, traz consigo toda uma gama de atribuições, diante das quais a adolescente pode se sentir despreparada.

Tal realidade nos possibilita compreender a variável faixa etária servindo como eixo central de aglutinações em torno desta representação. Quanto mais nova a adolescente, mais distante lhes parece a ascensão à fase adulta embasada pela conquista da maturidade. À medida que o final da adolescência se aproxima, maior a afinidade com as expectativas da vida adulta e de forma menos abrupta se incide a incorporação do novo papel de responsabilidade com os cuidados de outrem. Logo, tem-se instalado um movimento inverso na faixa etária mais alta do que o expresso pelas as adolescentes mais novas.

A variável NSED também exerceu forte influência na formação desta categoria temática. Quanto maior o NSED das adolescentes entrevistadas, mais intensamente se percebeu a 
transposição do papel de cuidada para cuidadora interferindo e caracterizando as representações acerca da gravidez na adolescência. As adolescentes de ambos os grupos NSED alto e baixo, apesar das diferenciações de condutas, estão agindo conforme o conteúdo de valores e significados circulantes em seus contextos sociais. Assim, uma explicação possível para esta distinção entre as condutas adotadas por estes grupos de pertença é o fato de, nas camadas mais populares da sociedade, a incorporação de atributos característicos de certa emancipação da figura do cuidador acontecer mais precocemente.

Já com relação às conotações positivas que tangenciam as representações sociais da gravidez na adolescência, emergem outras significações servindo de amálgama e determinando comportamentos diferenciados para as adolescentes. Assim, pode-se destacar que, para as adolescentes estudadas, principalmente as de NSED baixo, existem condicionantes favoráveis, gravitando em torno do tema gravidez na adolescência.

Essas adolescentes no processo de formação de suas representações favoráveis lançam mão da objetivação enquanto recurso constitutivo e, de tal forma, objetivam a gravidez atribuindo-lhe o significado de luz.

A gravidez seria um momento bom. A gravidez é uma luz. Seria uma luz, uma luz para a minha vida. (E17-17 anos/NSED baixo)

\section{CATEGORIA VI - Construção da Própria Família}

Na elaboração desta representação, o NSED se constituiu em forte crivo de leitura, pois das 15 aparições desse tema, 14 entrevistadas eram desse segmento. Fundamentadas pelo partilhar do significado comum de gravidez enquanto ponto de partida para a emancipação da família de origem e estruturação de um novo núcleo familiar, as adolescentes guiam suas ações e dão sentido às suas vidas.

Como uma possível explicação para esta especificidade, pode-se citar o fato de que em nossa sociedade ainda se mantém o ideário de que a menina desde cedo deve ser preparada para vida privada, para a vida doméstica e para assumir seu papel social de esposa e de mãe. As aspirações das adolescentes do sexo feminino, construídas a partir dessa trama, refletem este olhar voltado para o casamento, para ter filhos e para a consagração da família. Há uma ênfase na maternidade enquanto ápice da estruturação familiar, o que significa que é bom para a mulher ficar grávida, ter filhos e constituir família. Este ambiente desponta como seu espaço de ação, de reconhecimento legítimo e hegemônico graças ao status inquestionável de rainha do lar.

Em um estudo sobre a experiência de assumir uma gravidez na adolescência, os autores concluíram que, em geral, as adolescentes pobres, provenientes de famílias disfuncionais, de pouca instrução e cujas mães tiveram precocemente seu primeiro filho, de modo consciente ou não, vêem na gravidez uma forma de reescrita de sua história familiar ${ }^{17}$.

Diante do exposto, pode-se afirmar que a representação da gravidez na adolescência, para este grupo social específico (NSED baixo), emerge atrelada à necessidade de uma valorização e de um reconhecimento social. Essa ansiedade por ocupar um espaço de maior respeitabilidade na sociedade também pode ser explicada com base no senso comum vigente nas camadas mais populares da sociedade, onde escassez de opções de vida dimensiona a maternidade e os cuidados com a prole, a razão fim de toda atividade social feminina; ou seja, a gravidez completa o caminho "natural" da mulher, contemplando-lhe com o status social de "dona de casa", lugar máximo de destaque dentro do espaço doméstico (domínio tradicionalmente vinculado à mulher). A produção artística e a fala a conu ir ilıctram n nronnctn.

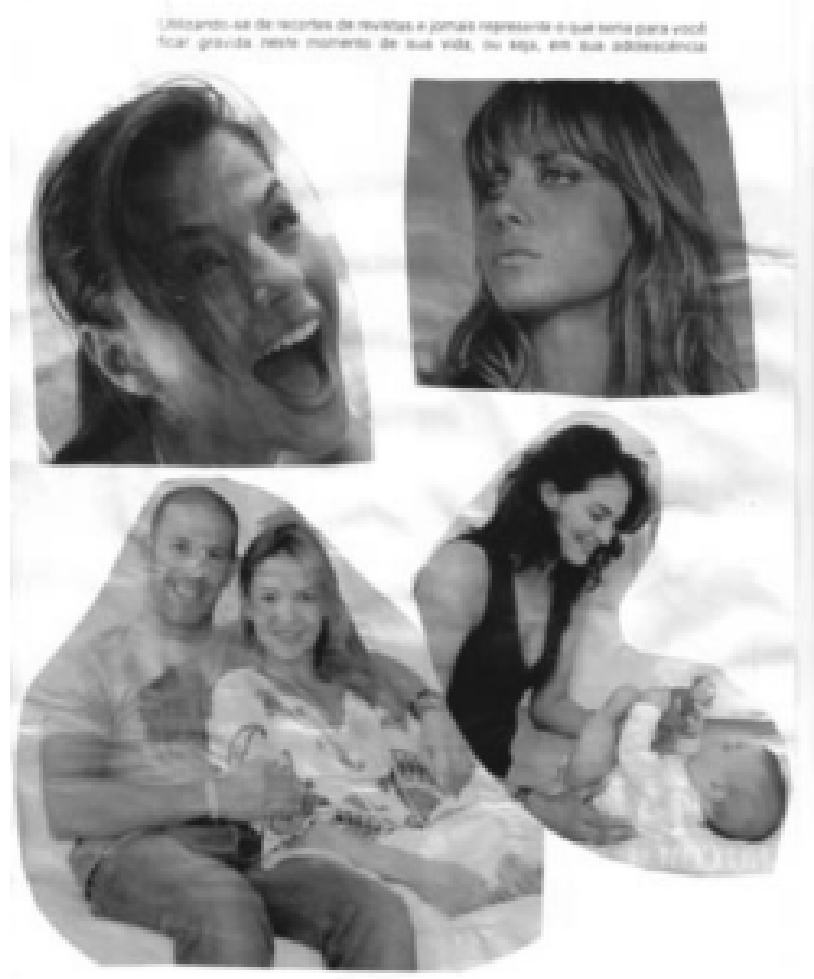

Eu ia procurar ele (o atual namorado) para a gente ficar junto, e ia cuidar (do bebê), né? (...) Se eu engravidasse, eu ia ficar feliz, eu ia ter a minha família [...]- (E8 - 15 anos/NSED baixo)

Quanto menor o NSED, mais a adolescente se distancia ao vislumbrar o desempenho de outros papéis sociais e maior é a sua percepção dentro do estereótipo que equaciona de maneira similar mulher e mãe, constituindo-se em desvio, uma anormalidade, não desejar isso.

\section{CATEGORIA VII: Ser Mãe: 0 Poder de Ser Mulher}

Esta representação também emergiu somente dentre 0 grupo de adolescentes de menor NSED, das 15 entrevistadas 
que referiram esse poder feminino, 14 eram desse segmento. Para estas adolescentes, a maternidade aparenta ser uma única forma de realização pessoal, o plano de vida ao qual a adolescente vai ao encontro.

Dentro desta perspectiva, é válido ressaltar que prevalece em nossa cultura a representação da maternidade como algo positivo e socialmente valorizado. Por isso, é fundamental que, ao buscarmos conhecer as representações acerca da gravidez na adolescência, atentemos para o fato de que as representações dos sujeitos se mostram como um produto social, ou seja, as adolescentes elaboram suas representações sobre a gravidez na adolescência a partir de seu contexto social, pois o conhecimento não é neutro, ele está impregnado e impregna a prática, ao orientar as escolhas e condutas dos indivíduos ${ }^{5}$.

A gravidez na adolescência é uma âncora que permite à jovem criar ou reforçar vínculos sociais. Através de um movimento de "empoderamento", ser mãe confere a esta adolescente maior prestígio na sociedade, ou seja, o ser mãe representa a potencialidade máxima da trajetória do feminino. Desde cedo, as meninas recebem estímulos que fortalecem sentimentos de identificação com as mães e, neste âmbito, desenvolvem comportamentos, atitudes e valores esperados da mulher. É um tipo de reconhecimento social que demonstra que a mulher cumpriu satisfatoriamente a expectativa que lhe é atribuída ao longo de toda sua formação: a reprodução.

(a gravidez) Eu acho que é a realização de toda mulher, ter uma pessoa e dar um filho para ela. [...] Para mim eu acho que quem não quer ter filho é porque... sei lá... Eu penso desse jeito, não posso ver criança que para mim já é minha. [...] Eu me vejo cuidando, criando - ( E20 - 18 anos/NSED baixo)

0 fio condutor que aproxima a idéia central desta categoria é o de que o domínio da esfera doméstica é por si só a mola mestra da realização pessoal do feminino. Para as adolescentes de NSED baixo, economicamente desfavorecidas, tem-se um contexto social caracterizado pela pouca ou nenhuma oportunidade de inserção social que não seja a maternidade e a vida doméstica. Logo, estas adolescentes representam a maternidade como mais viável, ou mesmo o único, caminho para sua inserção social.

\section{CATEGORIA VIII: Gravidez: Uma Benção Divina}

A representação da gravidez enquanto dom divino denota que as adolescentes atrelam a gravidez a uma dádiva de Deus, refletindo uma dimensão religiosa na representação social da gravidez, inclusive quando esta incide na adolescência. Esta categoria emergiu entre sete adolescentes, sendo seis de NSED baixo.

Na linha argumentativa de seus discursos, as adolescentes notoriamente estabeleceram uma conexão de suas intersubjetividades e do coletivo na construção dos saberes em torno do caráter divino presente na gravidez. Este saber não se apresentou apenas como um processo cognitivo aprendido pelo indivíduo no processo de adolescer, mas também como um fenômeno recheado de aspectos inconscientes, emocionais e afetivos que se fizeram marcantes tanto na produção como na reprodução das representações sociais da gravidez enquanto benção na significação deste grupo social. Exemplificando, destaca-se uma colagem com sua respectiva

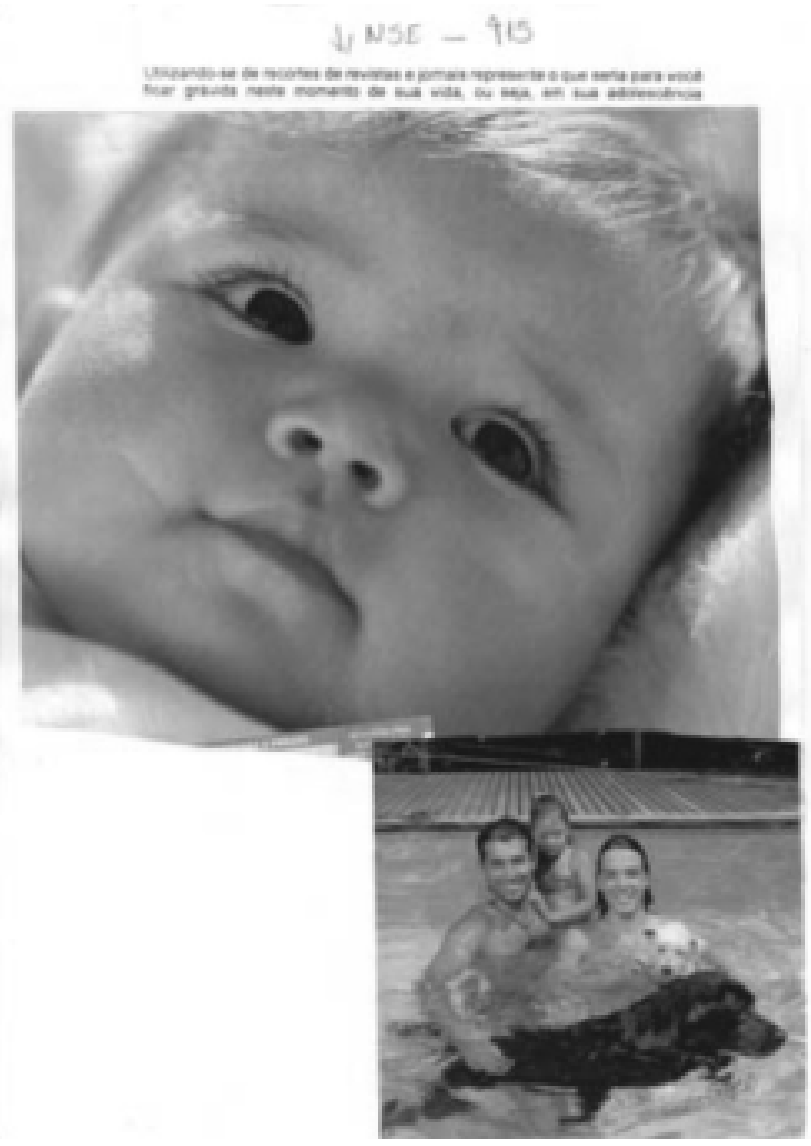

Se eu fosse mãe agora, estaria assim, toda boba. Mas até agora Deus não me deu este dom, ainda. [...] Uma gravidez para mim é uma vida que vem, que Deus manda, eu acho que éo jeito para acertar a vida da pessoa, dá mais alegria. Para mim é uma vida. [...] Quando você vai ver, é uma luz, assim, um neném-( E17-17 anos/NSED baixo)

0 poder divino foi mencionado como soberano e inquestionável, até mesmo quanto à incidência de uma gravidez fora do momento ideal. Deus/religião surge, neste contexto, como falta de autonomia diante da escolha do momento da gravidez. 0 fato de as entrevistadas confiarem a ocorrência da gestação, mesmo incidindo na adolescência, a decisão de Deus encontra fundamento na interpretação de Geertz ${ }^{18}$ ao relatar que as experiências que envolvem a perplexidade, 0 desconhecido, o inesperado, ou ainda o paradoxo moral impulsiona os homens para crenças em deuses, espíritos, assumindo o pressuposto de uma autoridade sobrenatural capaz 
de transformar realidades e solucionar questões se assim for de merecimento.

A religião serve de terreno para a compreensão dos acontecimentos cotidianos ao neutralizar o binômio profano/ santo, ancorando a própria gravidez no imaginário sagrado e objetivá-la enquanto designo supremo. É o imponderável traçando o destino do humano, que passa a aceitar sua condição de subordinação e delegar a Deus a direção de sua vida por intermédio do credo religioso.

\section{CONSIDERAÇÕES FINAIS}

A questão da gravidez na adolescência, mesmo sendo uma temática com vários estudos correlatos, apresenta um evidente caráter promissor em se tratando de produção científica, especialmente em abordagens que contemplem as dimensões bio-psico-histórico-culturais do ser adolescente.

Ao longo do desenvolvimento do trabalho, foi possível delinear a configuração de quatro grupos reflexivos, evento que nos faz refletir o quanto as divergências e convergências de representações são originadas no contexto sócio-econômicodemográfico específico de cada grupo de pertença. Isso porque as pessoas costumam interpretar o que lhes acontece, formar uma opinião sobre sua própria conduta e a das pessoas mais próximas e, daí, orientar suas ações em conformidade com essa interpretaçãa ${ }^{5}$. Ou seja, os indivíduos na relação com seus pares constroem suas representações, tecem uma visão subjetiva e social da realidade.

Percebemos que, apesar de a gravidez na adolescência se caracterizar, em representação hegemônica nos grupos estudados, como advento fora de hora e atrelado a outros constituintes de conotação negativa, ela também é elaborada e percebida pelos adolescentes de NSED baixo como evento gerador de condicionantes positivas. Evidencia-se, assim, uma dualidade inerente ao ser adolescente do sexo feminino de classes mais populares, que apesar de repetir um discurso social de inadequação e incompatibilidade entre a gravidez e a adolescência, tem a gestação representada como ícone do sagrado e da consagração máxima do ser mulher.

No entanto, o grupo de adolescentes de NSED alto e idade entre 10 e 15 anos representa a gravidez pelo viés único dos aspectos negativos e, na elaboração dessas representações, evidencia a difícil transição de cuidado para cuidadora. Por fim, as adolescentes de NSED alto e com mais de 16 anos, além de representarem a gravidez como algo eminentemente negativo, apresentam um diferencial no conteúdo das representações sociais, a atribuição à gravidez de comprometimento de planos futuros.

Concluímos desejosos que este estudo seja considerado relevante, na medida em que pode favorecer para redirecionar a assistência de enfermagem de maneira a encontrar modos de cuidar que incluam a diversidade de pertenças sociais-culturaiseconômicas das adolescentes em seu processo de adolescer e, assim, contribuir, de fato, para a apropriação de uma maior autonomia na escolha do momento da gravidez e, por conseguinte, para a garantia dos direitos sexuais e reprodutivos desta clientela singular.

\section{Referências}

1 Queiroz ABA, Arruda A. Refletindo sobre a saúde reprodutiva e a situação de infertilidade. Cad Saude Colet 2006; 14(1): 163-77.

2 Domingues CS, Alvarenga, AT. Identidade e sexualidade no discurso adolescente. Rev Bras Crescimento Desenvolv Hum 1997; 7 (2): 3268

3 Queiroz ABA, Arruda A, Tyrrell MAR. Desvendando a situação de infertilidade e seus reflexos no gênero feminino através do programa informatizado - ALCESTE. Escola Anna Nery Rev Enferm 2003 dez; 7(3): 388-97

4 Mandú ENT. Adolescência: saúde, sexualidade e reprodução: In: Adolescer: compreender, atuar, acolher. Projeto Acolher. Brasilia(DF): ABEn; 2001.

5 Moscovici S. A representação social da psicanálise. Rio de Janeiro (RJ): Zahar; 1978.

6 Polit DF, Hungler RBP. Fundamentos da pesquisa em enfermagem. Porto Alegre (RS): Artes Médicas; 1995.

7 Arruda A. Representações sociais: emergências e conflito na psicologia social. São Paulo (SP): Brasiliense; 1992.

8 Wagner W. História, memória e senso comum: representações sociais e interdisciplinariedade. In: Moreira ASP. Representações sociais: teoria e prática. João Pessoa (PB): Ed Universitária; 2001.

9 Bardin L. Análise de conteúdo. Lisboa (PO): Ed Setenta; 1979.

10 Jodelet $D$. Representations sociales: un domaine en expansion. In: Jodelet D. Les representations sociales. $2^{a}$ ed. Paris (FR): PUF; 1991.

11 Garcia TR. Cuidando de adolescentes grávidas solteiras. [tese de doutorado]. Ribeirão Preto (SP): Escola de Enfermagem de Ribeirão Preto/USP; 1996.

12 Abric JC. Les représentations sociales: aspects théorique. In: Abric JC, editor. Pratiques sociales et représentations. Paris (FR): PUF; 1994.

13 Reis AOA, Oliveira-Monteiro NR. Sexualidade e procriação na ótica de jovens de periferias sociais e urbanas. Rev Bras Crescimento Desenvolv Hum 2007 abr/jun; 17(2): 54-63.

14 Heilborn ML. Experiências da sexualidade, reprodução e trajetórias biográficas juvenis.In: Heilborn ML, Aquino EML, Bozon M, Knauth DR, organizadores. 0 aprendizado da sexualidade: reprodução e trajetórias sociais de jovens brasileiros. Rio de Janeiro RJ): Garamond /FIOCRUZ; 2006.

15 Safer J. Além da maternidade. São Paulo (SP): Mandarim; 2000.

16 Moscovici S. Representações sociais: investigações em psicologia social. Petrópolis (RJ): Vozes; 2003.

17 Gomez EG. Gênero muyer e salud en las americas.Washington (USA): OPS/OMS; 1993.

18 Geertz C. A interpretação das culturas. Rio de Janeiro (RJ): Livros Técnicos e Científicos; 1989. 